\title{
Proposta de uma matriz de correspondência entre indicadores de incertezas do ambiente organizacional e da governança relacional em redes
}

\author{
Proposal of a correspondence matrix model between organizational \\ environmental uncertainties indicators and relational governance in networks \\ Proposition d'une matrice de correspondance entre les indicateurs \\ d'incertitudes de I'environnemental organisationnel et la gouvernance \\ relationnelle dans les réseaux
}

Propuesta de una matriz de correspondencia entre indicadores de
incertidumbres del entorno organizacional y gobernanza relacional en redes

\author{
Maria Carolina de Arruda ${ }^{1}$ \\ Ernesto M. Giglio ${ }^{1}$ \\ Augusto Cezar D'Arruda ${ }^{1}$
}

Recebido em 02/09/2017; revisado e aprovado em 08/12/2017; aceito em 20/12/2017

DOI: http://dx.doi.org/10.20435/inter.v0i0.170

\begin{abstract}
Resumo: Investiga-se a proposição de correspondência entre as incertezas do ambiente organizacional e a construção social da governança relacional, definindo-se governança relacional como mecanismos de controle e defesa contra as incertezas. Foram investigadas duas redes de Cuiabá, e os dados sustentaram a proposição. Os benefícios teóricos e metodológicos são apresentar uma matriz operacional de pesquisa com um quadro de indicadores confiáveis, e o benefício gerencial é apontar distintas formas de gestão nos dois casos.

Palavras-chave: redes; governança relacional; incertezas ambientais organizacionais.
\end{abstract}

Abstract: We investigate the proposition of correspondence between the uncertainties of the organizational environment and the social construction of relational governance, defined as control and defense mechanisms against uncertainties. The research collected data from two Cuiabá networks and the results supported the proposition. The theoretical and methodological benefits are to give an operational model and a matrix of indicators and the management benefit is to point distinct forms of management in the two cases.

Keywords: networks; relational governance; environmental organizational uncertainty.

Résumé: Nous étudions la proposition de la correspondance entre les incertitudes de l'environnement et la construction sociale de la gouvernance relationnelle, est utilisé comme mécanisme de contrôle et de défense contre les incertitudes. La recherche a recueilli des données de deux réseaux de Cuiabá et les résultats ont soutenu la proposition. Les avantages théoriques et méthodologiques sont de présenter un modèle opérationnel et un cadre d'indicateurs fiables et l'avantage de gestion est de signaler différentes formes de gestion dans les deux cas.

Mots-clés: reseaux; gouvernance relationnelle; incertitudes organizationnels.

Resumen: El artículo investiga la propuesta de correspondencia entre las incertidumbres del ambiente y la construcción social de la gobernanza relacional, y se utiliza el concepto de gobernanza relacional como mecanismos de control y defensa contra las incertidumbres. Se recogieron datos de dos redes de Cuiabá y los resultados sustentaran la proposición. Los beneficios teóricos y metodológicos son presentar un modelo operativo y un cuadro de indicadores fiables y el beneficio gerencial es apuntar distintas formas de gestión en los dos casos.

Palabras clave: redes; gobernanza relacional; incertidumbre ambiental organizacional.

\footnotetext{
${ }^{1}$ Universidade Paulista (UNIP), São Paulo, São Paulo, Brasil.
} 


\section{INTRODUÇÃO}

Governança é uma das expressões amplamente investigada no campo de redes, com indicações da ordem de 80 mil no banco de dados Web of Science. Análise bibliográfica dos resumos dos artigos mais citados sobre governança em redes indica convergência do conceito de função de controle dos processos e do comportamento dos atores. A governança é o arranjo que possibilita a ação coletiva, na busca dos resultados (GRANDORI; SODA, 1995). Outra convergência é definir a governança como forma de incentivo para ações coletivas, buscando eliminar o oportunismo (WILLIAMSON, 1995; GRANDORI, 2006). Sobre essas duas vertentes, surgem divisões sobre governança formal, informal, estrutural, contratual, relacional; conforme a origem, a natureza da regra, aos papéis e práticas que ela determina.

Nesse leque de abordagens e divisões, surgem questões tais como fatores determinantes na formação de governança que é construida pelo grupo; se os mecanismos se modificam e se adaptam, ou são fixos; quais os efeitos da governança na coesão e eficiência do grupo; quais os efeitos nos resultados, sejam comerciais, ou de outra natureza; se o campo organizacional influencia na natureza da governança da rede.

Sobre esta última questão, o campo organizacional de uma tarefa, ou de um negócio, pode apresentar incertezas sobre as mudanças nesse mesmo campo. A incerteza de um campo organizacional é ponto importante na literatura de estratégia (JAUCH; KRAFT, 1986; PFEFFER; SALANCIK, 1978), com 33 mil indicações no banco de dados Web of Science, quando se colocam as expressões strategy e uncertainty. As expressões network e uncertainty também têm indicações da ordem de 30 mil, mas as expressões governance e uncertainty têm indicações da ordem de 2 mil. Quando associadas com network, as indicações são da ordem de 200. A leitura dos títulos dessas 200 indicações mostra ausência de estudos, modelos e práticas que integram governança e incertezas na perspectiva de redes.

No entanto, conforme alguns autores (MILLIKEN, 1987; WILLIAMSON, 1986; GRANDORI, 2006; JONES; HESTERLY; BORGATTI, 1997), são as incertezas do ambiente organizacional que levam à construção da governança. Para Jones, Hesterly e Borgatti (1997) e Grandori (1997), a governança na rede tem como função diminuir as incertezas, tanto das condições ambientais (climáticas), quanto das organizacionais (condições de mercado) e comportamentais.

Pode-se afirmar, conforme os argumentos e números apresentados, que o tema da relação entre incertezas e governança é colocado como importante, mas pouco investigado. Assim, o trabalho se justifica no fato de as redes necessitarem de constante adaptação, tendo em vista estarem em ambientes instáveis, seja sob os aspectos comerciais, políticos, seja sociais, comportamentais, nos quais existem incertezas, valorizando a necessidade de se criar uma governança. Infere-se, portanto, uma matriz de correspondência entre incertezas do ambiente organizacional e governança relacional em redes, esta última criada como forma de diminuir os efeitos das incertezas e criar segurança.

O artigo procura aprofundar o conhecimento sobre essa relação e apresenta a proposição P1: Diante das incertezas do ambiente organizacional e comportamentais, os atores de uma rede criam regras com a dupla função de diminuir os efeitos nos processos da rede causados por mudanças imprevisíveis e de controlar a ocorrência de comportamentos imprevisíveis.

Incerteza, portanto, é aqui colocada como evento imprevisível, independentemente do conhecimento de cada ator (que é outra corrente de definição de incerteza). Mudanças climáticas, 
modismos de consumo, alterações de forças políticas e econômicas, desastres ambientais, conflitos armados, inovações tecnológicas são exemplos de imprevisibilidades, mesmo que os analistas construam cenários alternativos a partir de alguns sinais de mudança.

A governança, por seu turno, é aqui definida como construção social para coesão e defesa do grupo (POWELL, 1990; GRANOVETTER, 1985). Quando a governança nasce de regras construídas pelo próprio grupo, dá-se o nome de governança relacional.

Construída a proposição, realizou-se nova busca no portal Web of Science e no portal Scielo com as expressões network e relational governance com filtro no título, para os últimos 10 anos, o que gerou indicações da ordem de 524 (520+4 respectivamente). A leitura dos títulos e resumos dos 100 primeiros, por ordem de data mais recente, mostrou a distribuição dos conceitos em duas grandes divisões: a governança como controle e a governança como coordenação, conforme apontada por alguns autores (PILBEAM; ALVAREZ; WILSON, 2012; IBERT; STEIN, 2012; SPAN et al., 2012; PARK; WILDING, 2014; RAEYMAECKERS, 2013; SCHUESLER; DECKER; LERCH, 2013).

Seja com função de controle, ou de coordenação, ou de incentivo, uma corrente afirma suas origens a partir de regras, práticas e normas do ambiente organizacional; gerando os contratos formais; e outra corrente afirma sua construção a partir dos relacionamentos entre os atores, o que é a governança relacional, foco neste artigo. A justificativa desse foco é sustentada por autores (CAO; LUMINEAU, 2015; LUO; LIANG; MA, 2013; GOO; HUANG, 2008; YEH, 2016; TEPIC et al., 2011) que defendem que a governança relacional é a origem e a base do equilíbrio e desenvolvimento de um grupo, no sentido de coesão e solução dos conflitos.

Outra justificativa do trabalho, de ordem gerencial, é que o conceito de governança relacional indica uma forma de gestão participativa, isto é, com decisões construídas pelos atores do grupo. Sobre o campo selecionado para esta investigação, que são cooperativas e associações, encontram-se debates muito importantes sobre as formas de gestão de grupos; o alcance de múltiplos objetivos (sociais, econômicos, políticos) e os sucessos de empreendimentos que surgem voluntariamente na sociedade, ou em conjunto com políticas públicas. Embora não seja o foco deste artigo, espera-se que a discussão dos casos possa trazer alguma contribuição para essa questão da gestão.

O outro braço da proposta é sobre incerteza. Na revisão, encontram-se várias afirmativas, desde modelos matemáticos, da engenharia e da informática, chegando na Administração com o sentido de mudanças imprevisíveis, ou falta de conhecimento (FOSTER; BORGATTI; JONES, 2011; JACOMOSSI; SILVA, 2016; MILLIKEN, 1987).

Já no campo específico de Redes, são raros os artigos encontrados, podendo-se citar Gravier (2007) e Leiblein (2003), sobre incerteza comportamental; Hui e Tsang (2006), sobre incerteza na tomada de decisão; Whitford (2003), sobre risco econômico; Carpenter e Frederickson (2001) sobre falta de informação; Gardelin, Rosseto e Verdinelli (2013), sobre inabilidade para se prever de modo preciso o ambiente organizacional. Nesses trabalhos, há o esforço de se considerar as incertezas que podem afetar uma rede, mas nenhum deles tratou da governança.

Considerando os propósitos do trabalho, aceita-se o conceito de incerteza como imprevisibilidade da ocorrência dos fenômenos, sem entrar no mérito do conhecimento das pessoas. 0 artigo aceita a existência de incertezas de fato, isto é, que afetam todos do grupo de maneira igual.

Os autores também aceitam o pressuposto de uma ligação indissociável entre a rede e o campo organizacional, isto, é, as organizações de uma rede fazem parte de um sistema (SERVA; DIAS; ALPERSTEDT, 2010), mantendo vínculos com as organizações desse sistema. As incertezas 
estão presentes em todo o sistema e uma parte do campo, que é a rede, busca se proteger de seus possíveis efeitos.

Como conclusão das reflexões e dos resultados da pesquisa bibliográfica, apresentam-se os Quadros 1 e 2, que resumem os princípios sobre governança e incerteza adotados no artigo.

O resumo dos princípios de governança relacional aceitos no artigo é mostrado no Quadro 1.

Quadro 1 - Resumo dos princípios de governança relacional

\begin{tabular}{|l|l|}
\hline Função básica & Controlar processos e comportamentos \\
\hline Origem & $\begin{array}{l}\text { (a) surge dos relacionamentos } \\
\text { (b) existe porque os contratos formais são limitados }\end{array}$ \\
\hline $\begin{array}{l}\text { Variáveis que influenciam na sua } \\
\text { origem e desenvolvimento }\end{array}$ & $\begin{array}{l}\text { (a) relações de confiança e de comprometimento } \\
\text { (b) incertezas do ambiente no qual a rede faz parte }\end{array}$ \\
\hline Natureza e características & São construídas e modificadas no próprio grupo \\
\hline
\end{tabular}

Fonte: Construção dos autores, 2019.

O resumo dos princípios de incerteza aceitos no artigo é mostrado no Quadro 2.

Quadro 2 - Resumo dos princípios de incertezas encontrados na revisão

\begin{tabular}{|l|l|}
\hline Definição & $\begin{array}{l}\text { Imprevisibilidade sobre ocorrências de fenômenos, tais como mudanças } \\
\text { climáticas }\end{array}$ \\
\hline Origem & Surgem de combinações aleatórias de variáveis \\
\hline Incerteza Ambiental & $\begin{array}{l}\text { Imprevisibilidades sobre fenômenos do campo organizacional que } \\
\text { afetam as redes, tais como choques econômicos, desastres ambientais, } \\
\text { revoluções tecnológicas. }\end{array}$ \\
\hline Incerteza Comportamental & $\begin{array}{l}\text { Imprevisibilidade sobre o comportamentos dos colegas do grupo, } \\
\text { especialmente o comportamento oportunista, negligente e errático. }\end{array}$ \\
\hline Natureza e características & Imprevisíveis, indefinidas, sempre presente (como possibilidade) \\
\hline
\end{tabular}

Fonte: Construção dos autores, 2019.

Apresentados os argumentos, a proposição, seus pontos de partida e a justificativa do trabalho, apresenta-se a teoria de base.

\section{RECORTE TEÓRICO SOBRE GOVERNANÇA E INCERTEZAS DO AMBIENTE ORGANIZACIONAL NAS REDES}

Considerando os pontos de partida aceitos no trabalho, constantes nos Quadros 1 e 2, a primeira base teórica advém do paradigma social de redes. O princípio desse paradigma é que as relações sociais constituem a trama, isto é, o contexto, que dirige, influencia e determina os processos, as decisões e os comportamentos dos atores da rede.

Conceitos repetidos na produção acadêmica, tais como embeddedness (GRANOVETTER, 1985), ação coletiva (OLSON, 1965), confiança e comprometimento (MORGAN; HUNT, 1994), redes como jogos de poder (ZAHEER; GOZUBUYUK; MILANOV, 2010; POWELL, 1990), economia solidária (LYON, 2015) atestam a presença e importância desse paradigma na explicação de redes. No presente artigo, a visão social de redes implica que a governança relacional nasce dessa teia de relacionamentos. 
A segunda base conceitual refere-se à valorização da confiança e do comprometimento. Há uma corrente de pensamento (MORGAN; HUNT, 1994; ZAHEER; GOZUBUYUK; MILANOV, 2010; JONES; HESTERLY; BORGATTI, 1997) afirmando que as categorias de confiança e de comprometimento constituem o pilar de formação, sustentação e desenvolvimento das redes. Neste artigo, considera-se que a governança relacional é um desses processos que se originam pelo pilar da confiança e do comprometimento. Em outras palavras, existindo um clima relacional de confiança e de comprometimento, é possível aos atores de um grupo conversarem e decidirem sobre seus mecanismos de ação coletiva.

A terceira base teórica advém de modelos conjuntivos entre relações sociais e governança. Trata-se de uma extensão do item anterior, agora buscando esclarecer a forma de conexão entre a base social e a governança relacional. A natureza dessa relação foi afirmada por Jones, Hesterly e Borgatti (1997) e Grandori (2006), no sentido de a base social gerar um contexto, um ambiente de grupo que possibilita que os atores discutam e decidam sobre regras do seu próprio grupo. Dito de outra forma, sem essa teia social, o grupo não se articula para discussão e solução de questões. No presente artigo, essa conjunção oferece o argumento sobre as condições sociais de origem da governança relacional. Quando as pessoas participam da formação das regras, se apropriam de uma identidade social (HASLAM et al., 1996) e há indícios de que o compromisso em cumprir essas mesmas regras é mais forte e presente do que em mecanismos formais de governança (RHODES, 1996).

O quarto item conceitual é sobre incerteza. Os textos a classificam em duas variações: (a) Incerteza do ambiente organizacional; (b) Incerteza comportamental.

A incerteza do ambiente organizacional é definida como imprevisibilidade da ocorrência de fenômenos, independentemente da percepção de cada ator (MILLIKEN, 1987; THOMPSON, 1967). Os fenômenos podem ser de ordem natural, como clima; ou organizacional, como leis e alterações de consumo. A incerteza comportamental é definida como imprevisibilidade do comportamento dos atores, especialmente comportamentos oportunistas e negligentes (GULATI, 1998). Diferente da incerteza do ambiente organizacional, aqui se aceita que o comportamento pode ser controlado em parte, criando-se incentivos para ações coletivas.

A última base conceitual trata da conjunção da governança relacional com as incertezas. Para Grandori (2006), a governança relacional pode ser considerada uma solução viável em circunstâncias de incertezas, já que os contratos formais são limitados aos eventos corriqueiros.

O modelo de governança de Jones, Hesterly e Borgatti (1997) afirma que os laços entre os parceiros podem reduzir a incerteza comportamental, já que comportamentos oportunistas acabam sendo conhecidos por todos. O modelo também inclui incertezas ambientais na origem da governança, tais como incertezas sobre demanda e sobre complexidade de tarefas.

O resumo dos princípios teóricos selecionados é apresentado no Quadro 3. 
Quadro 3 - Resumo dos conceitos teóricos adotados no trabalho

\begin{tabular}{|c|c|}
\hline Paradigma Social & $\begin{array}{l}\text { Relações sociais dirigem os rumos dos processos, decisões e } \\
\text { comportamentos de atores na rede }\end{array}$ \\
\hline $\begin{array}{l}\text { Governança Relacional - Condição } \\
\text { de emergência }\end{array}$ & $\begin{array}{l}\text { Surge a partir de um ambiente de colaboração, fundado em } \\
\text { confiança e comprometimento }\end{array}$ \\
\hline Governança Relacional - conceito & $\begin{array}{l}\text { Conjunto de mecanismos sobre ações coletivas, construído } \\
\text { a partir das relações entre os atores; buscando resolver } \\
\text { os problemas da tarefa do grupo, sejam eles de natureza } \\
\text { comportamental, como conflitos de interesses; sejam de } \\
\text { natureza ambiental, como imprevisibilidade de demanda. }\end{array}$ \\
\hline Governança Relacional - função & $\begin{array}{l}\text { Criar defesas contra imprevisibilidades do ambiente e do } \\
\text { comportamento das pessoas }\end{array}$ \\
\hline Incerteza Ambiental & $\begin{array}{l}\text { Imprevisibilidade da ocorrência de fenômenos, independente } \\
\text { da percepção de cada ator (MILLIKEN, 1987; THOMPSON, } \\
\text { 1967). A incerteza não pode ser controlada. Pode-se construir } \\
\text { defesas contra seus efeitos (GEERSBRO; RITTER, 2010; } \\
\text { MILLIKEN, 1987). }\end{array}$ \\
\hline Incerteza comportamental & $\begin{array}{l}\text { Imprevisibilidade do comportamento dos atores, } \\
\text { especialmente comportamentos oportunistas e negligentes } \\
\text { (Gulati, 1998). O comportamento pode ser controlado em } \\
\text { parte, por impor compromissos, obrigações e expectativas. }\end{array}$ \\
\hline $\begin{array}{l}\text { Ligação entre incerteza e } \\
\text { governança relacional }\end{array}$ & $\begin{array}{l}\text { É a proposta do artigo. A governança relacional surge como } \\
\text { forma de proteção contra incertezas ambientais e forma de } \\
\text { controle das incertezas comportamentais. }\end{array}$ \\
\hline
\end{tabular}

Fonte: Construção dos autores, 2019.

A Figura 1 resume a proposição. As partes sublinhadas constituem o foco da pesquisa.

Figura 1 - Desenho de Pesquisa sobre correspondência entre incertezas e governança

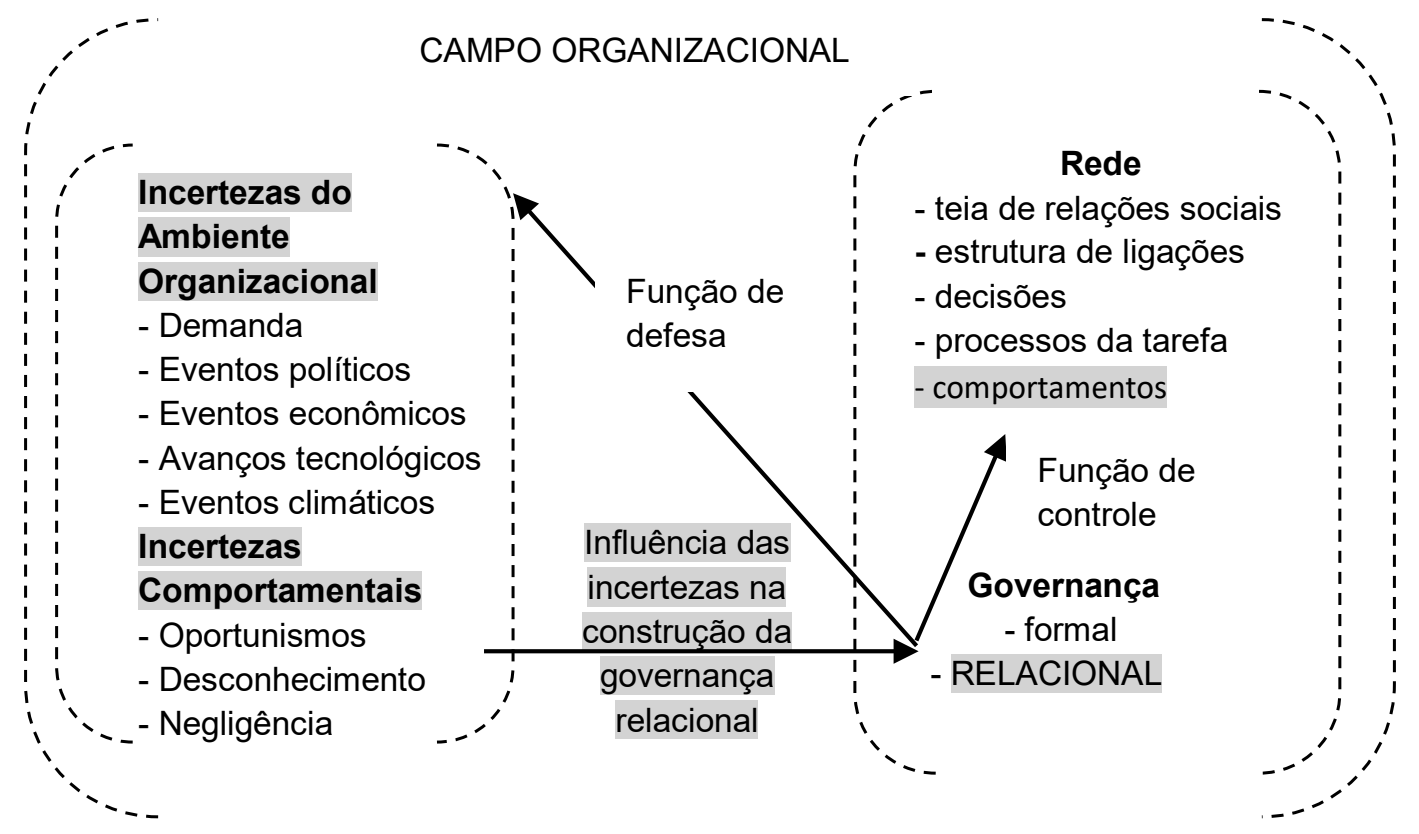

Fonte: Construção dos autores, 2019. 
A proposição é que a governança relacional é uma construção social, a partir de uma base de confiança e de comprometimento; com decisões sobre mecanismos de defesa contra incertezas do ambiente organizacional e de controle de comportamentos inadequados.

\section{METODOLOGIA}

Os primeiros passos metodológicos, já apresentados, foram realizar a revisão bibliográfica, buscando as convergências de conceitos; selecionar os pontos de partida teóricos que suportam a proposição e criar o desenho da pesquisa.

O próximo passo importante foi a construção de indicadores de incertezas e de governança, que se mostrassem operacionais e confiáveis nos testes. Os indicadores foram construídos a partir de afirmativas dos autores da teoria de base, como no texto de Jones, Hesterly e Borgatti (1997); de exemplos em trabalhos encontrados na revisão (BERTOLI, 2015; MILAGRES; SILVA; REZENDE, 2016) e a partir do conhecimento dos autores sobre as características das redes de associações de material reciclável, por exemplo, sobre decisões de distribuição de tarefas, ou de criação de fundo de emergência para quem necessitasse.

\subsection{Indicadores das categorias Governança Relacional, Incerteza do Ambiente Organizacional e Incerteza Comportamental}

Conforme Minayo (2007), há validade de se utilizar a expressão indicador em variáveis qualitativas. Nesse caso, eles servem como sinalizadores da realidade, isto é, evidenciam e sustentam a presença de certa realidade selecionada pelo pesquisador.

O Quadro 4 apresenta os indicadores.

Quadro 4 - Indicadores das categorias governança relacional, incerteza ambiental e comportamental

\begin{tabular}{|c|c|c|}
\hline Categoria & $\begin{array}{c}\text { Conceito } \\
\text { Dominante }\end{array}$ & Indicadores \\
\hline $\begin{array}{l}\text { 1. Sinais de } \\
\text { incerteza do } \\
\text { ambiente } \\
\text { organizacional }\end{array}$ & $\begin{array}{l}\text { Incerteza do } \\
\text { ambiente } \\
\text { organizacional } \\
\text { é a situação da } \\
\text { dificuldade, ou } \\
\text { incapacidade } \\
\text { dos atores de } \\
\text { um grupo para } \\
\text { conhecer e prever } \\
\text { com precisão o } \\
\text { desenrolar de } \\
\text { fenômenos no seu } \\
\text { campo de atuação. }\end{array}$ & $\begin{array}{l}\text { 1.1 Incertezas sobre a relação entre o crescimento econômico da } \\
\text { região e sua influência no grupo; } \\
\text { 1.2 Incertezas sobre a relação entre futuras tecnologias e sua } \\
\text { influência no negócio ou na tarefa do grupo; } \\
\text { 1.3.1 Incertezas sobre as mudanças políticas e sua influência no } \\
\text { grupo; } \\
\text { 1.3.2 Incertezas sobre possíveis mudanças comerciais e seus efeitos } \\
\text { no grupo; } \\
\text { 1.3.3 Incertezas sobre possíveis mudanças nas leis que possam } \\
\quad \text { afetar o grupo; } \\
\text { 1.4 Incertezas sobre as ações dos fornecedores e sua influência no } \\
\text { grupo; } \\
\text { 1.5 Incertezas sobre as ações dos movimentos dos concorrentes e sua } \\
\text { influência no grupo; } \\
\text { 1.6 Incertezas sobre desejos, demanda, necessidades e } \\
\text { comportamento dos consumidores e sua influência no grupo; e } \\
\text { 1.7 Incertezas sobre as mudanças ambientais e climáticas e sua } \\
\text { influência no negócio ou na tarefa. }\end{array}$ \\
\hline
\end{tabular}




\begin{tabular}{|c|c|c|}
\hline Categoria & $\begin{array}{c}\text { Conceito } \\
\text { Dominante }\end{array}$ & Indicadores \\
\hline $\begin{array}{l}\text { 2. Sinais de } \\
\text { incerteza de } \\
\text { comportamento }\end{array}$ & $\begin{array}{l}\text { Incerteza } \\
\text { comportamental é a } \\
\text { imprevisibilidade do } \\
\text { comportamento de } \\
\text { um parceiro }\end{array}$ & $\begin{array}{l}2.1 \text { Incertezas sobre a ética e a conduta correta conforme as regras } \\
\quad \text { do grupo; } \\
2.2 \text { Incertezas sobre o comprometimento dos parceiros que integram } \\
\quad \text { o grupo; } \\
2.3 \text { Incertezas sobre os objetivos individuais, dos parceiros que } \\
\quad \text { integram o grupo, conflitantes com os coletivos; } \\
\text { 2.4 Incertezas sobre o comportamento comercial oportunista dos } \\
\quad \text { parceiros; } \\
\text { 2.5 Incertezas sobre a intenção dos parceiros de continuidade no } \\
\quad \text { grupo; e } \\
\text { 2.6 Incertezas sobre disposição de arcar com os custos coletivos. }\end{array}$ \\
\hline $\begin{array}{l}\text { 3. Sinais de } \\
\text { governança } \\
\text { relacional }\end{array}$ & $\begin{array}{l}\text { Governança } \\
\text { relacional é a } \\
\text { governança que } \\
\text { nasce dos acordos } \\
\text { e valores das } \\
\text { relações sociais. }\end{array}$ & $\begin{array}{l}\text { 3.1 Regras de acesso restrito } \\
\text { 3.1.1 Existem regras de restrição de acesso às informações do } \\
\text { grupo para aqueles que não fazem parte do grupo; } \\
\text { 3.1.2 Dependendo da informação, existem restrições para uma } \\
\text { parte dos integrantes do grupo; } \\
\text { 3.2 Controle social } \\
\text { 3.2.1 A coordenação e o controle das atividades do grupo se dão } \\
\text { por todos do grupo; } \\
\text { 3.2.2 Existe uma rotina de encontro para criação e ajustes das } \\
\text { regras do grupo; } \\
\text { 3.3 Definição de papéis } \\
\text { 3.3.1 Existência de regras sobre a definição de função ou atribuição } \\
\text { de cada um desse grupo; } \\
\text { 3.4 Existência de uma comissão que decide } \\
\text { 3.4.1 A coordenação das atividades do grupo se dá por uma } \\
\text { comissão eleita por todos; } \\
\text { 3.5 Definição e existência de hierarquia } \\
\text { 3.5.1 Existência de regras para eleger pessoas que representam e } \\
\text { gerenciam o grupo; } \\
\text { 3.5.2 Existência de regras para eleger pessoas que têm autoridade } \\
\text { para controlar as outras pessoas no que diz respeito a seguir } \\
\text { as regras; } \\
\text { 3.6 Sistemas de controle e sanções } \\
\text { 3.6.1 Existência de algum controle ou alguma forma de vigilância do } \\
\text { comportamento do outro; } \\
\text { 3.6.2 Existência de regras de controle e regras de combate aos } \\
\text { comportamentos oportunistas; } \\
\text { 3.7 Incentivos formais/ informais para continuar no grupo } \\
\text { 3.7.1 Existência de gratificações, internas ao grupo, para a } \\
\text { permanência dos integrantes do grupo; } \\
\text { 3.7.2 Existência de gratificaç̃̃es, externas ao grupo, para a } \\
\text { permanência dos integrantes do grupo; } \\
\text { 3.8 Diretrizes para legitimação pública } \\
\text { 3.8.1 Existência de regras e/ou ações para conseguir } \\
\text { reconhecimento do governo, do mercado e da sociedade; } \\
\text { 3.8.2 Existência de regras e/ou ações para conseguir legalização } \\
\text { perante o governo; e } \\
\text { 3.9 Diretrizes para buscar suporte do governo, do mercado e da } \\
\text { sociedade } \\
\text { 3.9.1 Existência de ações/tarefas para conseguir algum apoio } \\
\text { financeiro ou de infraestrutura do governo, do mercado e da } \\
\text { sociedade. }\end{array}$ \\
\hline
\end{tabular}




\begin{tabular}{|l|l|l|}
\hline \multicolumn{1}{|c|}{ Categoria } & \multicolumn{1}{c|}{$\begin{array}{c}\text { Conceito } \\
\text { Dominante }\end{array}$} & \multicolumn{1}{c|}{ Indicadores } \\
\hline & & $\begin{array}{l}\text { O plano geral é investigar situações que mostram as falhas da } \\
\text { governança. } \\
\text { 4.1 Existência de casos de falhas na prevenção de incertezas sobre os } \\
\text { acontecimentos do ambiente organizacional (ou seja, casos em que o } \\
\text { grupo foi surpreendido por evento ambiental); }\end{array}$ \\
$\begin{array}{l}\text { 4. Sinais da } \\
\text { interface entre } \\
\text { Incertezas e } \\
\begin{array}{l}\text { Governança } \\
\text { Relacional }\end{array}\end{array}$ & $\begin{array}{l}\text { A governança } \\
\text { relacional pode ser } \\
\text { considerada uma } \\
\text { solução viável em } \\
\text { circunstâncias de } \\
\text { incertezas. }\end{array}$ & $\begin{array}{l}\text { 4.2 Existência de casos de falhas no controle do comportamento (ou } \\
\text { sejasos em que o grupo foi surpreendido por um comportamento } \\
\text { oportunista de um ator); } \\
\text { 4.3 Existência de casos de falhas de aplicação das regras (ou seja, as } \\
\text { regras foram criadas, mas se mostraram impossíveis, ou inoperantes } \\
\text { na hora de aplicar); } \\
\text { 4.4.1 Existência de casos de falhas quanto à concordância da } \\
\text { existência de algumas regras; e }\end{array}$ \\
& $\begin{array}{c}\text { 4.4.2 Existência de casos de falhas quanto ao cumprimento de } \\
\text { algumas regras (ou seja, as regras existem, mas nem todos } \\
\text { concordam com elas); }\end{array}$ \\
\hline
\end{tabular}

Fonte: Construção dos autores, 2019.

\subsection{Plano da pesquisa}

A pesquisa se caracteriza por ser um estudo de casos múltiplos, qualitativa, descritiva, exploratória e interpretativa, já que investiga categorias não métricas, descrevem-se práticas e processos e se aplica um referencial teórico para interpretar os dados.

Para a investigação, foram selecionadas duas redes na região de Cuiabá, MT: (a) A rede que inclui uma associação de material reciclável de Várzea Grande, caracterizada como rede de economia solidária, com objetivos de inclusão social e comerciais; (b) A rede que inclui o Shopping Popular de Cuiabá/MT, que atualmente funciona com objetivo predominantemente comercial, mas na sua história já teve como objetivo principal a legitimação da atividade do vendedor de varejo popular, o camelô.

Foram utilizadas duas fontes de coletas: Entrevistas e dados de fontes secundárias. Para as duas fontes foi elaborado um roteiro de coleta, a partir dos indicadores. A realização das entrevistas seguiu um roteiro semiestruturado, utilizando a técnica da bola de neve para seleção dos sujeitos. Como dados de fontes secundárias, foram utilizados regimento interno da Associação dos Catadores de Várzea Grande (Asscavag- a associação que é o foco da rede de economia solidária), estatutos, ata de reuniões, termo de parceria entre o Instituto Gama e a Asscavag, acordo de cooperação técnica, financeira e contratos que são documentos provenientes de sindicatos, de associações, de secretarias de governo, de pesquisas do Instituto Brasileiro de Geografia e Estatística (IBGE), de organizações do terceiro setor e entrevistas técnicas com consultores, gerentes e profissionais que participaram do início, ou desenvolvimento das redes.

Os dados obtidos na forma de discursos foram analisados conforme os preceitos da análise temática de Bardin (2011), e os dados obtidos na forma de quadros, tabelas e gráficos foram codificados conforme se referiam a algum indicador. 


\section{APRESENTAÇÃO E ANÁLISE DOS DADOS DA REDE DE ECONOMIA SOLIDÁRIA DE CATADORES DE MATERIAL RECICLÁVEL}

Essa rede está localizada no município de Várzea Grande, no Mato Grosso, e a organização solidária foco é a Asscavag. Dados de fontes secundárias, incluindo entrevistas técnicas, mostram que o modo de operação entre as organizações caracteriza o formato em rede, já que existem evidências de interdependência, partilha de informações, objetivo coletivo que dirige as ações, complexidade de tarefa (especialmente a tarefa de coleta, que necessita de uma logística que uma associação não consegue realizar sozinha) e existência de regras sobre ações coletivas entre os atores pessoas e organizações. A presença dessas características legitima tratar-se de um formato em rede, portanto apropriado para a investigação.

A Asscavag surgiu em 2009, com o objetivo principal de oferecer melhor qualidade de vida e de trabalho para os catadores, que recolhiam materiais recicláveis do lixão de Várzea Grande, MT. Essa associação possui cerca de 32 catadores associados e entre fornecedores e compradores de materiais recicláveis são aproximadamente 15 empresas, formando a rede de primeiro nível. Já a rede ampliada tem mais 23 organizações envolvidas, dentre elas governo, BNDES, terceiro setor, empresas de grande porte com programas de responsabilidade social.

Para o seu desenvolvimento e operacionalidade, a associação criou vínculos com o governo, Ongs, indústrias locais que têm projetos sociais, condomínios e compradores de material reciclável. Essas parcerias trouxeram benefícios, tais como fluxo constante de material a ser triado, auxílio em documentação de trabalho, cursos de capacitação e cursos de alfabetização.

Uma das parcerias gerou um acordo de cooperação técnica e financeira entre o Banco Nacional de Desenvolvimento Econômico e Social-BNDES e o Instituto Gama, unidade de responsabilidade social de uma indústria local. O contrato dessa parceria mostra normatização, com pouca abertura para ajustes entre as partes. Entre as possibilidades estavam: ajustes de datas de envio de relatórios; escolha da entidade proponente para a elaboração de ações específicas (como cursos de capacitação); forma de representação da associação nas votações.

Sobre as fontes primárias de dados, o Quadro 5 é o resumo da análise de conteúdo das cinco entrevistas realizadas. Um dado convergente é o discurso de forte presença de relações de comprometimento entre os cooperados, no seu esforço de legitimação e continuidade da cooperativa. Esses laços fortes de comprometimento e de confiança possibilitaram a criação de regras que são seguidas pelo grupo, sustentando parte da proposição deste artigo, sobre a existência de uma trama social na emergência da governança relacional. 
Quadro 5 - Análise de conteúdo das entrevistas da rede de material reciclável

\begin{tabular}{|c|c|}
\hline Sujeito 1 & $\begin{array}{l}\text { Associado fundador da Asscavag. Antes era catadora de material reciclável no lixão e } \\
\text { mais tarde decidiu criar a associação, juntamente com mais duas famílias, também de } \\
\text { catadores. O discurso indicou incertezas sobre o futuro das pessoas e da associação } \\
\text { (pelas exigências contratuais) e como o grupo precisou decidir rapidamente uma forma } \\
\text { de organização e legitimação para garantir sua existência. }\end{array}$ \\
\hline Sujeito 2 & $\begin{array}{l}\text { Associada, faz parte de uma das famílias fundadoras da associação. É representante } \\
\text { do Movimento Nacional dos Catadores Recicláveis (MNCR), trabalhando para } \\
\text { o fortalecimento dos catadores, a conscientização da população a respeito da } \\
\text { classificação dos materiais recicláveis e a coleta seletiva. A análise do discurso } \\
\text { indica um raciocínio de separação entre pessoas internas da associação e os outros } \\
\text { (políticos, empresas, outros catadores que querem tirar proveito do grupo), o que } \\
\text { indica incerteza comportamental. "Contra" esses outros, afirma que a associação exige } \\
\text { dedicação integral ao trabalho coletivo e que cada um se esforce para criar rotinas, } \\
\text { regras e práticas de proteção do grupo contra os oportunistas. O sujeito afirma que } \\
\text { a associação é uma família a ser protegida. A análise indica relação entre a incerteza } \\
\text { comportamental e as regras criadas no grupo. }\end{array}$ \\
\hline \multirow{3}{*}{$\begin{array}{l}\text { Sujeitos } 3 \\
\text { e } 4\end{array}$} & $\begin{array}{l}\text { Entrevista conjunta, sendo um deles consultor do Projeto de desenvolvimento de } \\
\text { cooperativas na região e outro é gerente da unidade de responsabilidade social da } \\
\text { indústria local. A função de ambos é ajudar e verificar a correta aplicação dos recursos } \\
\text { financeiros e materiais da Asscavag. }\end{array}$ \\
\hline & $\begin{array}{l}\text { A análise indicou que as regras construídas pela associação estão sendo eficientes } \\
\text { para resolver os problemas de comportamento dos associados e que as incertezas } \\
\text { ambientais tais como legislação, tecnologias e funding estão previstas nas regras dos } \\
\text { contratos. O discurso é que a rotina da rede é sempre seguir as regras já provadas } \\
\text { como eficientes. }\end{array}$ \\
\hline & $\begin{array}{l}\text { O discurso, já com convergência dos discursos anteriores, indica que entre organizações } \\
\text { a governança é predominantemente burocrática, formal e pré formatada, ao passo que } \\
\text { na associação, que pode ser considerada uma sub rede da rede maior, a necessidade } \\
\text { de organização do trabalho exige decisões coletivas rotineiras, caracterizando o } \\
\text { predomínio da governança relacional. }\end{array}$ \\
\hline Sujeito 5 & $\begin{array}{l}\text { Representante de uma empresa compradora de material, sendo parceiro da associação } \\
\text { desde o início. A atuação de sua empresa é basicamente comercial, sem ações sociais, } \\
\text { ou solidárias. Dessa forma, seu discurso não tem evidencias de governança relacional, } \\
\text { apenas tratos comerciais dentro de regras de mercado. Esta entrevista mostrou que } \\
\text { o lado comprador da rede da Asscavag pode não seguir objetivos sociais, tal como } \\
\text { ocorre na ponta fornecedora (moradores, condomínios, empresas) e na relação entre } \\
\text { apoiadores (prefeitura, ONGs e empresas com projetos sociais). É uma rede assimétrica } \\
\text { nos objetivos dos diversos atores. }\end{array}$ \\
\hline
\end{tabular}

Fonte: Construção dos autores, 2019.

\subsection{Resposta ao problema de pesquisa}

Os dados indicaram a necessidade de se analisar a rede entre as organizações e também a rede interna da associação Asscavag, porque existem distinções importantes.

A rede interorganizacional na qual a Asscavag está inclusa apresenta evidências de dominância da governança contratual, isto é, de mecanismos já prontos para serem implantados, com regras econômicas, legais e de políticas públicas. A governança relacional, no sentido de regras criadas pela rede, aparece em alguns casos, tais como decisões sobre cursos de capacitação. Nesse exemplo, a Associação negociou com as outras organizações sobre quem (qual perfil) deveria dar cursos para eles, exigindo que fosse alguém da localidade, que conhecesse o contexto. 
A rede intraorganizacional da Asscavag apresenta dominância de governança relacional, até por exigência de o grupo organizar-se para atender as demandas contratuais e de mercado. A função basicamente social da Associação contrasta com os objetivos comerciais dos compradores, com objetivos políticos da prefeitura e com objetivos fiscais e sociais da indústria local que apoia o projeto. As incertezas mais dominantes se referem à legislação, continuidade do apoio da indústria local, ajuda da sociedade na separação do material, comportamento dos cooperados (alguns com histórico de violência e desajustes sociais), o que exige decisões sobre regras.

Assim, a proposição sobre correspondência entre governança relacional e incertezas se sustenta mais claramente para a rede intraorganizacional da Asscavag, e a maior parte dos exemplos se referem a controles comportamentais.

Em termos gerenciais, não há interferência direta das organizações de apoio na gestão da Asscavag. O apoio da prefeitura e da empresa Gama está na infraestrutura de local e de equipamentos. O cruzamento dos dados, incluindo uma visita ao local, indica que a gestão é eficiente no seu papel de inclusão social, mas incipiente no seu objetivo comercial.

\section{APRESENTAÇÃO E ANÁLISE DOS DADOS DA REDE DE ORGANIZAÇÕES DE ECONOMIA POPULAR NA CIDADE DE CUIABÁ}

A organização foco dessa rede, o Shopping Popular de Cuiabá, está localizada na cidade de Cuiabá, em Mato Grosso, sendo um conjunto de vendedores ambulantes que antes estavam dispersos pelas ruas do centro da cidade. A partir da iniciativa da prefeitura local e das pressões dos lojistas, criou-se um espaço específico para esses ambulantes, com infraestrutura necessária para o comércio, no ano de 1995.

O Shopping Popular de Cuiabá, MT, constitui-se de aproximadamente 450 lojistas. Já a rede na qual o shopping popular está inserido, como ator central, tem cerca de sete organizações envolvidas diretamente na comercialização e a prefeitura. Dados de fontes secundárias, incluindo entrevistas técnicas com dois representantes da prefeitura e um do Shopping, mostram que o modo de operação entre as organizações caracteriza o formato em rede, já que existem evidências de interdependência, partilha de informações, objetivo coletivo que dirige as ações, complexidade de tarefa (no sentido de legitimar uma atividade que se caracterizava pela ilegalidade). A presença dessas características legitima tratar-se de um formato em rede, portanto apropriado para a investigação.

O início do Shopping foi muito difícil para os atores porque foi doado o local, mas não a infraestrutura, e o grupo precisou se organizar de maneira rápida e juridicamente legal para legitimar seu negócio. Essas ações são exemplos de governança relacional, porque as partes envolvidas, especialmente o Shopping e a prefeitura, tiveram que construir as bases de relacionamento a partir do zero, sem modelos a serem seguidos. Paralelamente, a administração do Shopping trabalhava para unir os microempresários, que não tinham cultura de ação coletiva. Um grande resultado do grupo foi a legitimação da Cooperativa de Compras do Comércio Popular de Mato Grosso (Coocomp/MT) por parte do governo do Estado, que legalizou a compra e venda dos produtos de varejo popular.

Essa legalização foi fundamental para mudar a imagem da população sobre os vendedores, passando de camelôs para empresários, com todo o sentido positivo da palavra e foi importante para marcar a ação coletiva do grupo (que passou a fazer compra coletiva, com o nome do Shopping). Também possibilitou a integração social e comercial dos vendedores entre si, agora 
donos de microempresas. Os fatos alavancaram as vendas no Shopping, tornando-o referência de compra na cidade. Quando esse estágio foi atingido, o objetivo social e de identidade do empresário caiu para o segundo plano, surgindo o objetivo comercial como o predominante.

A governança relacional dessa rede, portanto, está muito mais no seu passado do que na atualidade. Nesse ponto, vale comentar que é um bom exemplo de regras que nasceram de uma construção social e depois se formalizaram nos contratos comerciais e éticos que cada empresário assinou. Essa evolução mostra que a divisão encontrada na literatura sobre governança relacional distinta da governança formal pode ser discutida.

Na esteira de objetivo comercial, a última conquista relevante do grupo foi a assinatura de um contrato de uso do local por trinta anos, com a contrapartida de sustentabilidade da origem dos produtos, de qualidade de vida dos colaboradores e obrigações de revitalização e manutenção do local por parte do Shopping. Atualmente o Shopping constitui-se de 500 bancas dos mais variados produtos, com maior concentração em vestuário e eletrônicos.

A análise dos dados de fontes secundárias indica dominância de governança relacional voltada para a solução das incertezas comportamentais tanto dos antigos camelôs, quanto de lojistas da região e outros impactados pela presença de vendedores nas ruas do centro (por exemplo, os hotéis). As incertezas do ambiente organizacional adquiriram importância no segundo momento da história, quando o Shopping já se colocava como organização competitiva, que precisava resolver as incertezas do negócio, como qualidade de produtos.

Sobre dados de fontes primárias, o Quadro 6 apresenta a análise das três entrevistas realizadas. Vale lembrar que foi utilizado o critério de exaustão para encerrar a coleta na terceira entrevista.

Quadro 6 - Análise das entrevistas da rede do Shopping Popular de Cuiabá

\begin{tabular}{|l|l|}
\hline Sujeito 1 & $\begin{array}{l}\text { Representante do setor administrativo do Shopping Popular, na parte de comunicações, } \\
\text { estando há três anos na rede. O discurso indica maior ocorrência de governança } \\
\text { relacional na análise intraorganizacional, desenvolvida para fazer frente às incertezas } \\
\text { ambientais e comportamentais. Considerando os resultados comerciais do Shopping, } \\
\text { as regras acordadas estão resolvendo a parte de imprevisibilidade comportamental dos } \\
\text { associados. Esses resultados positivos conferem ao Shopping um poder de atração, com } \\
\text { vários pedidos para entrar e com comprometimento dos que lá estão. As incertezas } \\
\text { ambientais estão sendo atacadas por regras formais já existentes, sobre questões } \\
\text { ambientais, legais e comerciais. }\end{array}$ \\
\hline $\begin{array}{l}\text { A resposta da pesquisa, portanto, é a sustentação da correspondência da governança } \\
\text { relacional e incertezas quando se analisa a rede interna da Shopping, mas não se } \\
\text { sustenta na rede de organizações do varejo popular. }\end{array}$ \\
$\begin{array}{l}\text { Lojista do Shopping Popular, está no grupo há mais de 15 anos. O discurso do sujeito, } \\
\text { convergente com dados secundários, é que houve muito esforço de ajustes e acordos } \\
\text { no início do Shopping, diminuindo de intensidade após a legitimação da organização. } \\
\text { No que se refere às relações entre as incertezas ambientais e comportamentais com } \\
\text { a governança relacional, pode-se afirmar que as regras presentes no grupo estão } \\
\text { resolvendo a maioria dos problemas relativos ao comportamento dos associados. Já } \\
\text { os possíveis imprevistos relacionados às incertezas ambientais estão em sua maioria } \\
\text { previstos nas regras formalizadas no estatuto, ou no regimento interno da associação. } \\
\text { Existem sinais de governança relacional na rede intraorganizacional do Shopping } \\
\text { Popular, que buscam a prevenção e controle das incertezas comportamentais, isto é, } \\
\text { sobre as ações dos lojistas. O discurso não mostrou evidências da governança relacional } \\
\text { na rede interorganizacional. }\end{array}$ \\
\hline
\end{tabular}




\begin{tabular}{|l|l|}
\hline Sujeito 3 & $\begin{array}{l}\text { Lojista do Shopping Popular, está no grupo desde o início e atualmente é participante } \\
\text { da Administração. Seu discurso afirma que as regras estão resolvendo a maioria dos } \\
\text { problemas de operação do Shopping e que elas foram construídas ponto a ponto, } \\
\text { conforme o caso. Esses problemas são predominantemente comportamentais dos } \\
\text { lojistas do shopping. O sujeito descreveu exemplos dessas construções, tais como } \\
\text { a proibição de estocar caixas no corredor, ou a proibição dos lojistas estacionarem } \\
\text { no Shopping; indicando a construção social passo a passo da governança relacional. } \\
\text { Algumas regras, tais como proibição de venda de produtos ilegais, se referem tanto a } \\
\text { defesa de incertezas ambientais, quanto comportamentais. } \\
\text { Tal como se inferiu na análise dos dados secundários, aqui também se conclui que a } \\
\text { governança relacional foi construída passo a passo na história do Shopping; algumas } \\
\text { regras se tornaram formais (como proibição de venda de produtos ilegais) e afirma o } \\
\text { sujeito que hoje em dia os problemas do Shopping são pequenos. }\end{array}$ \\
\hline
\end{tabular}

Fonte: Construção dos autores, 2019.

\subsection{Resposta ao problema de pesquisa}

A análise dos dados indica correspondência entre a governança relacional e as incertezas comportamentais e do ambiente organizacional, quando se considera a rede interna da organização foco, o Shopping Popular. A solução de concentrar os antigos camelôs em um local, trouxe desafios ao grupo, que precisou se organizar, trabalhar em conjunto (que não era o padrão) e criar regras conforme os eventos imprevisíveis se apresentavam.

Já a rede interorganizacional, com a prefeitura, compradores, fornecedores, prestadores de serviços de segurança, lojistas da cidade, caracteriza-se atualmente por uma governança formal, contratual, com regras padronizadas de funcionamento do Shopping, de legalidade dos empresários, de formas de comercialização e de contrapartidas do Shopping no entorno.

Os resultados indicam uma história que se desenvolveu em dois eixos. Por um lado, as organizações da rede desenvolveram mecanismos formais de operação do Shopping, até com cuidado além dos padrões normais (como o controle diário de origem dos produtos vendidos) e, por outro lado, os atores do Shopping se viram diante do desafio de se organizarem e criarem um espaço social e comercial legitimado pela rede e pela população. No início, portanto, objetivos comerciais uniam-se com objetivos sociais, políticos e legais, até que a situação chegou num ponto de equilíbrio e passou a predominar o objetivo comercial.

A proposição, portanto, se sustenta quando se considera o passado da rede e quando se considera a análise intraorganizacional do Shopping.

Unindo-se os dados das duas redes, o Quadro 7 apresenta as correspondências encontradas entre incertezas e governança. 
Quadro 7 - As correspondências de indicadores de incertezas e de governança encontradas em duas redes do Mato Grosso

\begin{tabular}{|c|c|}
\hline Indicadores de Incertezas & Indicadores de Governança \\
\hline $\begin{array}{l}\text { 1.3.2 Possíveis mudanças } \\
\text { comerciais e seus } \\
\text { efeitos no grupo }\end{array}$ & $\begin{array}{l}\text { 3.4.1 A coordenação se dá por uma comissão eleita por todos. } \\
\text { 3.9.1 Ações/tarefas para apoio financeiro ou de infraestrutura do } \\
\text { governo, do mercado e da sociedade. }\end{array}$ \\
\hline $\begin{array}{l}2.1 \text { Ética e a conduta } \\
\text { correta conforme as } \\
\text { regras do grupo }\end{array}$ & $\begin{array}{l}\text { 3.2.1 Coordenação e controle das atividades do grupo se dá por todos } \\
\text { do grupo. } \\
\text { 3.2.2 Existe uma rotina de encontros para criação e ajuste das regras } \\
\text { do grupo. } \\
\text { 3.4.1 A coordenação se dá por uma comissão eleita por todos. } \\
\text { 3.5.2 Existência de regras para eleger pessoas que tenham autoridade. } \\
\text { 3.7.1 Existência de gratificações, internas ao grupo, para a } \\
\text { permanência dos integrantes no grupo. } \\
\text { 3.8.2 Regras e/ou ações para conseguir legalização. }\end{array}$ \\
\hline $\begin{array}{l}\text { 2.2 Comprometimento do } \\
\text { parceiros que integram } \\
\text { o grupo }\end{array}$ & $\begin{array}{l}\text { 3.2.1 Coordenação e controle das atividades do grupo se dá por todos } \\
\text { do grupo. } \\
\text { 3.2.2 Existe uma rotina de encontros para criação e ajuste das regras } \\
\text { do grupo. } \\
\text { 3.5.1 Existência de regras para eleger pessoas que representam e } \\
\text { gerenciam o grupo. } \\
\text { 3.8.1 Regras e/ou ações para reconhecimento do governo, do mercado } \\
\text { e da sociedade. }\end{array}$ \\
\hline $\begin{array}{l}\text { 2.3 Os objetivos individuais } \\
\text { dos parceiros do } \\
\text { grupo, conflitantes } \\
\text { com os objetivos } \\
\text { coletivos }\end{array}$ & $\begin{array}{l}\text { 3.2.1 Coordenação e controle das atividades do grupo se dá por todos } \\
\text { do grupo. } \\
\text { 3.2.2 Modo de decisão das regras do grupo. } \\
\text { 4.4.2 Existência de casos de falhas quanto ao cumprimento de } \\
\text { algumas regras. }\end{array}$ \\
\hline $\begin{array}{l}\text { 2.6 Disposição de arcar } \\
\text { com os custos } \\
\text { coletivos }\end{array}$ & $\begin{array}{l}\text { 3.4 Existência de uma comissão que decide. } \\
\text { 3.6.1 Existência de algum controle ou alguma forma de vigilância do } \\
\text { comportamento do outro. }\end{array}$ \\
\hline
\end{tabular}

Fonte : Construção dos autores, 2019.

A primeira análise do Quadro 7 é sobre a dominância de indicadores de incerteza comportamental. Nos dois casos, mesmo sendo redes que têm objetivos comerciais, a preocupação maior é com o comportamento das pessoas. Para controlar essa incerteza, os mecanismos são participação de todos, reuniões constantes, eleição democrática de representantes, formas de controle das ações.

A segunda análise é sobre a constância de presença do item 3.2.1- sobre participação de todos. Conforme Moreno (1978), a participação total e democrática é um mecanismo utilizado em grupos para criar a percepção de segurança e controle das pessoas, além de criar o compromisso de participação constante.

O conteúdo do que é decidido, no entanto, é distinto nas duas redes. A rede solidária valoriza as regras de inclusão social, e a rede do Shopping busca sua posição competitiva. Essa diferença indica que o fator de objetivos da rede, que não faz parte do rol de incertezas, tem um papel importante na construção da governança. O objetivo social da rede solidária, por exemplo, leva à regra de se aceitar pessoas com problemas de inclusão social, como ex-presidiários, ao passo que o objetivo comercial atual da rede de negócios do Shopping leva à regra de só aceitar 
empreendedores com ficha limpa. De forma indireta, portanto, a pesquisa indicou um fator controlável, o objetivo da rede, como influenciador da governança.

Outra discussão é de ordem metodológica. Os indicadores se mostraram operacionais, ou seja, aplicáveis, e confiáveis, isto é, capazes de coletar a presença do conteúdo ao qual se referiam e apontar diferenças entre as duas redes. Essa condição de operacionalidade e confiabilidade dos indicadores é uma contribuição metodológica importante do artigo, já que é raro encontrar indicadores qualitativos válidos na produção acadêmica brasileira.

Outra discussão, embora não seja o foco do artigo, é sobre a gestão das organizações foco. A Asscavag, organização foco da rede solidária, tem um estilo de gestão centralizada na figura da presidente, valorizando o objetivo social, com regras lábeis de inclusão social, porém as regras sobre o negócio não tornam a organização autossuficiente. Já o Shopping, organização foco da rede de negócios, tem um estilo gerencial clássico de competição no varejo popular, com regras rígidas de inclusão de novos atores, tendo perdido sua função social inicial.

\section{COMENTÁRIOS FINAIS}

A proposta do artigo foi propor e verificar a correspondência entre incertezas e governança relacional nas redes, quando se define governança relacional como construção de mecanismos que surgem no próprio grupo, com o objetivo de defesa e controle sobre as incertezas do ambiente organizacional e incertezas comportamentais. O esforço se justifica pelo fato de as redes estarem inseridas em ambientes de constantes modificações, parte delas imprevisíveis, sejam comerciais, políticas, sociais, sejam comportamentais, valorizando o papel da governança relacional na condução do grupo.

A revisão bibliográfica mostrou a raridade de modelos para essa composição entre incertezas e governança, levando os autores a construírem indicadores, que se mostraram operacionais e confiáveis. O quadro de indicadores constitui um benefício metodológico importante, pronto para ser replicado e validado.

A resposta obtida foi que, nos dois casos, uma rede de economia solidária e uma rede de varejo popular, encontraram-se poucos sinais de governança relacional na análise interorganizacional e sinais mais presentes na rede intraorganizacional das duas organizações foco, a Asscavag na rede de economia solidária e o Shopping Popular de Cuiabá, na rede de varejo popular.

O resultado contribui teoricamente para a compreensão e discussão da correspondência entre incertezas e a governança relacional. Autores clássicos colocam a governança como eixo central das redes (WILLIAMSON, 1986; GRANDORI, 1997; PROVAN; KENIS, 2007), mas pouco se investigou sobre como a construção desses mecanismos se associa com o ambiente no qual a rede está inserida. $O$ trabalho sugere que artigos futuros podem adicionar os fatores de incerteza na investigação da configuração da governança de uma rede.

O resultado da pesquisa vem de acordo com afirmativas de Jones, Hesterly e Borgatti (1997), Grandori (2006), Koka, Madhavan e Prescott (2006) sobre a governança relacional surgir em função das incertezas e ser a solução dessas mesmas incertezas. A pesquisa sustentou a primeira parte das assertivas dos autores, sobre a governança relacional ser uma construção de resposta sobre as incertezas.

A segunda parte das assertivas, sobre os resultados, não é o foco do trabalho, mas relatos espontâneos indicaram duas formas distintas de governança, com duas formas de gestão 
nas organizações foco e, como consequência, com resultados distintos. A Asscavag persegue o objetivo de inclusão social, mas sofre as consequências de sua ineficiência comercial, ao passo que o Shopping perdeu seu objetivo social e se marca cada vez mais como empresa competitiva. A questão dos empreendimentos solidários, com organizações que nascem com pequeno porte, raramente são investigados na perspectiva de redes, especialmente os casos de fracasso, ou progresso lento. Nessa discussão, incluem-se aspectos de dinâmica de grupo e aspectos de gestão. A discussão sobre gestão, que é um ponto importante das políticas públicas de inclusão social, precisa ser mais investigada, e o presente artigo oferece indicadores para o diagnóstico e possível plano de ação.

Os parágrafos anteriores levam a outro ponto, que é sobre o conceito de governança. Conforme citado na revisão, a ideia dominante de governança é sobre a funcionalidade do grupo e os resultados obtidos. A pesquisa mostrou que um grupo pode criar regras de defesa razoavelmente eficientes contra as incertezas e, mesmo assim, não alcançar seus resultados. A Asscavag é um exemplo. A associação construiu várias regras para controle do comportamento dos atores, visto que alguns deles têm um histórico de violência e desajuste social, mas essas regras não se vinculam diretamente com os resultados comerciais.

Sobre as variáveis confiança e comprometimento como mediadores na construção da governança relacional, os dados sustentaram a afirmativa, especialmente na rede da Asscavag, em que o comprometimento, a esperança, a confiança, a fé dos atores constituíram a trama social que dirigiu a construção de regras.

Finalmente, sobre o Shopping Popular de Cuiabá, a história contada pelos sujeitos mostra que no início tudo precisou ser combinado entre os atores, até o momento em que o Shopping e a prefeitura assinaram um acordo de cooperação, iniciando a era de governança formal contratual. Este é um exemplo de regras que nasceram de uma construção social e depois se formalizaram nos contratos comerciais e éticos que cada empresário assinou. Essa evolução mostra que a divisão encontrada na literatura sobre formas distintas de governança é discutível.

Talvez investigadores possam realizar pesquisas historicistas, com a hipótese que a governança relacional está no início de tudo. Pesquisas desse tipo poderiam quebrar certas divisões aceitas e utilizadas em pesquisas tais como governança formal e informal.

\section{REFERÊNCIAS}

BARDIN, L. Análise de conteúdo. São Paulo: Edição 70, 2011.

BERTOLI, N. A confiança e o comprometimento como eixos organizadores dos estados de redes: proposta, argumentação e estudo de casos do agronegócio da região Norte do Paraná. 2015. Dissertação (Mestrado em Administração)- Universidade Paulista (UNIP), São Paulo, 2015.

CAO, Z.; LUMINEAU, F. Revisiting the interplay between contractual and relational governance: a qualitative and meta-analytic investigation. Journal of Operations Management, v. 33-34, p. 15-42, 2015.

CARPENTER, M.; FREDERICKSON, J. Top management teams, global strategic posture, and the moderating role of uncertainty. Academy of Management Journal, v. 44, n. 3, p. 533-45, 2001.

FOSTER, P.; BORGATTI, S.; JONES, C. Gatekeeper search and selection strategies: relational and network governance in a cultural market. Poetics, v. 39, n. 4, p. 247-65, 2011. 
GARDELIN, J.; ROSSETO, C.; VERDINELLI, M. O relacionamento entre a incerteza ambiental e o comportamento estratégico na percepção dos gestores de pequenas empresas. Revista de Administração, São Paulo, v. 48, n. 4, p. 702-15, out./dez. 2013.

GEERSBRO, J.; RITTER, T. External performance barriers in business networks: uncertainty, ambiguity, and conflict. Journal of Business \& Industrial Marketing, v. 25, n. 3, p. 196-201, 2010.

GOO, J.; HUANG, C. Facilitating relational governance through service level agreements in IT outsourcing: an application of the commitment-trust theory. Decision Support Systems, v. 46, n. 1, p. 216-32, 2008.

GRANDORI, A. Innovation, uncertainty and relational governance. Industry and Innovation, v. 13, n. 2, p. 127-33, 2006.

GRANDORI, A. An organizational assessment of inter-firm coordination modes. Organization Studies, v. 18, n. 6, p. 897-925, 1997.

GRANDORI, A.; SODA, G. Inter-firm networks: antecedents, mechanisms and forms. Organization Studies, v. 16, n. 2, p. 183-214, mar. 1995.

GRANOVETTER, M. Economic action and social structure: a theory of embeddedness. American Journal of Sociology, v. 91, n. 3, p. 481-510, nov. 1985.

GRAVIER, M. Supply chain network evolution: demand-based drivers of interfirm governance evolution. 2007. Dissertation (Doctor of Philosophy)- University of North Texas, Texas, 2007.

GULATI, R. Alliances and network. Strategic Management Journal, v. 19, p. 293-317, 1998.

HASLAM, A.; OAKES, P.; TURNER, J.; MCGARTY, C. Social identity, self-categorization, and the perceived homogeneity of ingroups and outgroups: the interaction between social motivation and cognition. In: SORRENTINO, R.; HIGGINS, E. (Ed.). Handbook of motivation and cognition: the interpersonal context. New York: Guilford Press, 1996. v. 3, p. 182-222.

HUI, E.; TSANG, A. The inter-organizational relationship in a multi-contractor business network. Journal of Quality in Maintenance Engineering, v. 12, n. 3, p. 252-66, 2006.

IBERT, O.; STEIN, A. Spatialities of governance- spatial imaginations associated with market, hierarchy, networks and communities. Geography Compass, v. 6, n. 10, p. 602-16, 2012.

JACOMOSSI, F.; SILVA, M. Influência da incerteza ambiental na utilização de sistemas de controle gerencial em uma instituição de ensino superior. Revista de Gestão, São Paulo, v. 23, n. 1, p. 75-85, 2016.

JAUCH, L.; KRAFT, K. Strategic management of uncertainty. Academy of Management Review, v. 11, n. 4, p. 777-90, out. 1986.

JONES, C.; HESTERLY, W.; BORGATTI, S. A general theory of network governance: exchange conditions and social mechanisms. Academy of Management Review, v. 22, n. 4, p. 911-45, out. 1997.

KOKA, B.; MADHAVAN, R.; PRESCOTT, I. The evolution of interfirm networks: environmental effects on patterns of network change. Academy of Management Review, v. 31, n. 3, p. 721-37, 2006.

LEIBLEIN, M. The choice of organizational governance form and performance: predictions from transaction cost, resource-based, and real options theories. Journal of Management, v. 29, n. 6, p. 937-61, 2003. 
LYON, S. The hidden labor of fair trade. Labor: Studies in Working-Class History of the Americas, v. 12, n. 1/2, p. 159-76, 2015.

LUO, Y.; LIANG, F.; MA, Z. The effects of contractual governance and relational governance on construction project performance: an empirical study. International Journal of Digital Content Technology and its Applications, v. 7, n. 8, p. 741-9, 2013.

MILAGRES, R.; SILVA, S.; REZENDE, O. Governança cooperativa. In: BRASIL. Conselho Nacional de Secretários de Saúde. CONASS Debate - Governança Regional das Redes de Atenção à Saúde. Brasilia: CONASS, 2016. p. 14-48. (Série CONASS Debates, 6).

MILLIKEN, F. Three types of perceived uncertainty about the environment: state, effect, and response uncertainty. Academy of Management Review, v. 12, n. 1, p. 133-43, jan. 1987.

MINAYO, M. O desafio do conhecimento. 10. ed. São Paulo: Hucitec, 2007.

MORENO, J. Psicodrama. São Paulo: Cultrix, 1978.

MORGAN, R.; HUNT, S. The commitment-trust theory of relationship marketing. Journal of Marketing, v. 58, n. 3, p. 20-38, 1994.

OLSON, M. The logic of collective action. Cambridge: Harvard University, 1965.

PARK, C.; WILDING, M. An exploratory study on the potential of social enterprise to act as the institutional glue of network governance. The Social Science Journal, v. 51, n. 1, p. 120-9, 2014.

PFEFFER, J.; SALANCIK, G. The external control of organizations: a resource dependence perspective. New York: Harper \& Row, 1978.

PILBEAM, C.; ALVAREZ, G.; WILSON, H. The governance of supply networks: a systematic literature review. Supply Chain Management, v. 17, n. 4, p. 358-76, 2012.

POWELL, W. Neither market nor hierarchy: network forms of organization. Research in Organizational Behavior, v. 12, p. 295-336, 1990.

PROVAN, K.; KENIS, P. Modes of network governance: structure, management and effectiveness. Journal of Public Administration Research and Theory, v. 18, n. 2, p. 229-52, 2007.

RAEYMAECKERS, P. From a bird's eye view? A comparative analysis of governance and network integration among human service organizations. Journal of Social Service Research, v. 39, n. 3, p. 416-31, 2013.

RHODES, R. The new governance: governing without government. Political Studies, v. 44, n. 4, p. 652-67, 1996.

SCHUESLER, E.; DECKER, C.; LERCH, F. Networks of clusters: a governance perspective. Industry and innovation, v. 20, n. 4, p. 357-77, 2013.

SERVA, M.; DIAS, T.; ALPERSTEDT, G. Paradigma da complexidade e teoria das organizações: uma reflexão epistemológica. Revista de Administração de Empresas - RAE, São Paulo, v. 50, n. 3, p. 276-87, jul./set. 2010.

SPAN, K. et al. The relationship between governance roles and performance in local public interorganizational networks: a conceptual analysis. American Review of Public Administration, v. 42, n. 2, p. 186-201, 2012. 
TEPIC, M. et al. The role of structural and relational governance in creating stable innovation networks: insights from sustainability-oriented Dutch innovation networks. Journal on Chain and Network Science, v. 11, n. 3, p. 197-211, 2011.

THOMPSON, J. Organizations in action. New York: McGraw-Hill, 1967.

WHITFORD, J. After the outsourcing: networks, institutions, and the new old economy. 2003. PhD thesis (Department of Sociology)- The University of Wisconsin, United States, 2003.

WILLIAMSON, O. Transaction cost economics and organization theory. In: SMELSER, N. J.; SWEDBERG, R. (Ed.). The handbook of economic sociology. Princeton: Princeton University Press, 1995. p. 77-107.

WILLIAMSON, O. The economic institutions of capitalism. New York: Free Press, 1986.

YEH, Y. Critical influence of relational governance on relationship value in strategic supply management. European Business Review, v. 28, n. 2, p. 137-54, 2016.

ZAHEER, A.; GOZUBUYUK, R.; MILANOV, H. It's the connections: the network perspective in interorganizational research. Academy of Management Perspectives, v. 24, n. 1, p. 62-77, 2010.

\section{Sobre os autores:}

Maria Carolina Arruda: Mestre em Administração pelo Programa de Mestrado em Administração da Universidade Paulista (UNIP). E-mail: carol90.arruda@gmail.com, Orcid: http://orcid.org/0000-0001-5570-7407

Ernesto Michelangelo Giglio: Pós-Doutor pela Universidade Federal de Lavras (UFLA). Doutor em Administração pela Universidade de São Paulo (USP). Mestre em Administração pela Pontifícia Universidade Católica de São Paulo (PUC-SP). Professor e pesquisador do Programa de Mestrado em Administração da Universidade Paulista (UNIP), na linha de Abordagens Sociais em Redes. E-mail: ernesto.giglio@gmail.com, Orcid: http://orcid.org/0000-0001-6193-1421

Augusto Cézar D’arruda: Mestre em Administração pelo Programa de Mestrado em Administração da Universidade Paulista (UNIP). E-mail: augusto.arruda@ifmt.edu.br, Orcid: http://orcid.org/0000-0002-6817-5937 